before the tenth day of convalescence; and I know of such even after the man had been instructed as to the prostrating effect. Some of these observations may appear frivolous, but the saving of most of the doubtful cases depends so much on observance of all the details of diet and strength-saving, that I have run the risk of being prolix in order to state them. If only a few lives can be saved, the death-rate is made to comport with the possible, and it matters little whether they are saved by drugs administered, or through the common sense instructions of physician and attendants.

Notes:

I am almost certain that I saved the life of an esteemed physician by deceiving him as to his temperature. In disgust that so strong a man could not get up a fever higher than $39 \mathrm{C}$. or $39.5 \mathrm{C}$., (when it was, in fact, at one time $4 \mathrm{I}$ C.), he concluded that he was not so very sick after all. His three weeks' convalescence with yellowness of eyes and skin and extreme prostration fully evidenced the danger he had been in.

A priest, sick in an upper room, heard some ladies speak of the death (which occurred a moment before) of the commander of the fort, and of the necessity of keeping him ignorant of the fact until his crisis had passed. By a strong assertion of his will he decided not to be alarmed if the news should come to him, and not to ask the usual question about his now dead friend. He recovered; but if he had been startled by the sad news he would have vomited, collapsed and died.

A young man, with physically favorable prospects, conceived that a fellow-boarder was in love with his perhaps fatally ill wife. His inability to protect her by personal attention caused such distress of mind as to continue his fever until the sixth day in spite of all care and effort, and death resulted. His wife was only saved by concealing the fact of her husband's death for twelve days.

I have little fault to find with other plans of management as to medicine, but only give what I have reason to be satisfied with.

Salicylate of soda, carbolate of soda, et al., are useless. Pilocarpin has failed to meet my expectations. Large doses of calomel as a purge causes loss of three to six hours valuable time. The "three times three" treatment is useless in early vomiting cases-i. e., 3 grs. each of quinine, calomel and Dover's powder every three hours. As a febrifuge and diaphoretic it is of service. I have seen patients die with "liver pads" on them, and have removed them to put on a sinapism.

"Liver medicines" are of service in preventing the antecedent constipation, and thus tend to lighten attacks, but they do not prevent.

The "fever cot" is dangerous, expensive, requires two or three attendants on every patient, and is not infallible, as I saw the inventor die on one under his own directions.

The Secretary of the Section has furnished the following brief notes of the discussion which followed the reading of the foregoing paper-[EDIroR]:

Prof. H. F. Campbell, of Georgia, stated that he was impressed by the comprehensiveness of detail exhibited by Dr. Murray in his treatment of the subject. But basing his remarks upon his own experiences of the disease, said he recommended phlebotomy and the administration of emetics and cathartics, in certain cases, and laid particular stress upon the administration of quinine and liquid food.

Prof. Palmer, of Michigan, joined in the discussion; and Dr. Elliott, of Pennsylvania, objected strenuously to venesection, but advocated diaphoresis, and advised moderation in the use of therapeutic agents.

Dr. A. N. Bell, of New York, advocated diaphoresis, the use of sulphur and magnesia to produce catharsis, and absolute physical and mental quietude during convalesence.

Dr. Franklin, of Ohio, favored depletion by the use of calomel, and a strict diet during convalesence.

Gen. Flwell, of Ohio, was invited to a seat in the Section, and favored the audience with his experiences of yellow fever, at Port Royal, in 1862.

Dr. J. B. Hamilton, Surgeon-General of U. S. Marine Hospital service, closed the discussion on Dr. Murray's paper, stating that he believed in the contagiousness of yellow fever, in the value and advisability of quarantine, and urged quarantining; disinfection and cleansing as means of prophylaxis against the fever.

\section{MILK SICKNESS.}

BY WILLIAM MORROW BEACH, M.D., LONDON, OHIO.

[A Paper read before the Section on Medicine, of the American Medical Association, at Cleveland, Ohio. at the Session of June 5 th, 6 th, 7 th, and 8 th, 1883.$]$

I believe milk sickness to be a disease sui generis. In Madison county, Ohio, where I was born and raised, I presume nearly one-fourth of the pioneers and early settlers died of this disease; nor is its cause entirely eradicated there, or in many other districts of country where it has ever been known to prevail. Its principal fields have been Western Pennsylvania, Ohio, Kentucky, Tennesseee, Illinois, Indiana, and Michigan; and it has probably never been known in New England, west of the great American Desert, nor in any of the countries of the Old World. Its existence as a specific diseases has generally been discredited by the writers of medical literature in the eastern cities; and I think it is nowhere mentioned in any text book on theory and practice I have ever read.

The disease in the lower animals is called "trembles;" and " milk sickness," when it affects the human species. The disease is most common in the late summer and early autumn; but it occasionally occurs in the winter season.

Among domestic animals the trembles usually first affects unweaned calves, or lambs or colts. This would be expected, as the poison seeks elimination, or is eliminated in part, through the emunctory of the lacteal secretion; and the unweaned are subjected to the double cause-the cause that affects the mother, added to the poisoned milk it nurses. 
It next affects the other animals of the herd that are not giving milk; and the milk-giving animals last of all. This holds true with cattle, goats, sheep and horses.

The poison, whatever it is, is specific. The milk, the butter, the flesh of an animal suffering with trembles or in the prodromic stage of trembles, or bordering on the prodromic stage, transmit, or are liable to transmit, the disease to other animals that partake of them.

Wild animals are no less and no more exempt than domestic animals. The wolf, the fox, the wild cat, the wild hog and the turkey-buzzard that partook of the dead body of a deer that had died of the trembles, in the pioneer days of the infected districts, were as liable to contract the disease as the dog, the cat, the hog, the turkeybuzzard, or the fox that eat of the dead body of the .calf or other domestic animal of a later day.

\section{ETIOLOGY.}

1st. Many of the pioneers, as well as many wellinformed laymen and physicians of the present time, attribute the cause to the ingestion of some vegetable by herbivorous animals. These advocates are, and have been about equally divided between the eupatorium ageratoides and the rhus toxicodendron as the vegetable that contains the specific poison.

2d. Others have claimed, and still claim, that it is contracted by the herbivora drinking from certain sources of water supply contaminated with the specific poison.

$3^{\text {d. }}$ Others have claimed that its origin is malarial - marsh misamatic.

4th. That it is of a gaseous or mineral origin, and may be breathed, drank with the water, or ingested as it settles on and adheres to vegetation.

$5^{\text {th. }}$. That it is produced by spores, bacteria, or some microscopical fungi or disease germ.

In the consideration of its etiology a few well established facts should be borne in mind.

ist. The trembles are seldom met with in a wet season.

2d. In exceptionally dry seasons it may be confidently expected-in localities where the cause is known to exist-if domestic animals are not cared for by the thoughtful owner.

3 d. In fields where the flora may be supposed to be identical, it may be contracted in one field and not in the other.

$4^{\text {th. It }}$ Is unknown on open prairies or in cultivated fields that have been well opened to the sun and have become "tame," although the fields may not ever have been plowed.

$5^{\text {th. It }}$ is so safe, that in the experience of my life-time I have known of no departure from the rule - that domestic animals may roam with impunity through the infected districts anywhere, through the day time, providing they are brought to the inclosure or corral before nightfall, and kept there until the fogs and dews have dispersed on the following morning. All the pioneers with whom I have ever conversed hold to this theory, and it fully accords with my own observations.

6th. Wild and unimproved lands, densely timbered, seem to be the favorite haunts of the poison; nor does the quality of the soil or the character of the soil seem to influence the danger or prevalence of the trembles in herbivorous animals that are exposed at night. The rule holds good in the low lands of Ohio, Indiana, the groves of Illinois, or the high and rugged lands of Kentucky and Tennessee, so far as my sources of information have reached. I have long held the conclusion that the theory of vegetable ingesta alone is not based on satisfactory grounds. Within a few miles of where I live I have known inclosed lands, both in Madison and Clark counties, where trembles will develop during any summer of protracted dry weather, when they would not develop of an ordinarily wet summer; while the flora would be supposed to remain the same from year to year. One claim, however, renders this conclusion less conclusive, and that is that in very dry summers the grass crop becomes so much exhausted that the herbivora are driven to eat of such plants as they might otherwise reject.

But on my own farm, near London, Madison county, Ohio,-composed mostly of level, black, alluvial soil-within the last fifteen years I have cleared up and improved from its natural state about seven hundred acres, over much of which the rhus toxicodendron and the eupatorium ageratoides were abundant, and yet no case of trembles has ever occured there to the best of my knowledge and belief. And the leaves and the tender twigs of the rhus toxicodendron are relished and kept closely trimmed by horses, cattle and sheep.

As to the third, or marsh miasmatic theory, $I$ think the cause cannot be identical, as the trembles and milk sickness have never been known, it is supposable, in other countries, or in many sections of our own country, where different forms of malarial disease have always been known to prevail abundantly.

As to the fourth, or deleterious water supply theory, I think there is something in it. In very dry seasons, the water supply runs low, and the source of supply, in general, probably becomes stagnant and impure.

Within three miles of where I live, I know of three tracts of woodland, of forty or fifty acres each, which remain uncultivated, as they are retained in that condition to keep up the timber supply for the farms. These woodlands are pastured off until about the month of June each year, and again utilized in winter for feed lots for hogs, cattle, etc., with almost certain safety to the stock; but were the stock left there over into the months of July, August or September, in a dry season, trembles would almost certainly appear, as the experiment has not failed, in a dry summer, within the past seventy years. Some seasons, the venturesome owners keep thinking that they will use them for just a few days longer in the summer; when the appearance of turkey buzzards hovering over the woods in large numbers, suggests to them that the food these scavengers covet lies below them, dead of the trembles.

These three pieces of woodland are a mixture of low alluvial and dry elevations, or ridges, timbered mostly with white oak. To rid them of their danger, it would only be necessary to cut off the timber, and let the sunlight in upon the bare unshaded ground. 
In one of these pieces of woodland, the water supply is from a spring, which for many years was the water supply for a household of poor non-paying squatters, and in the twenty-eight years that I have attended professionally all families who have lived there, no case of milk sickness has ever occurred, nor more than the usual amount of remittents or intermittents; but no one ever lived there that owned a cow, or were more exposed by reason of milk, butter, cheese or diseased meats, than their neighbors who lived on cultivated farms.

I accept the theory as to the cause of trembles, that it has its origin in disease germs or spores, bacteria, microscopic fungi, etc.; but whatever its cause, I think it is evident that it is

1. Specific.
2. Infectious.
3. Incubative.

PREDISPOSING CAUSES.

Perhaps the most general predisposing cause is fatigue. I should think that half of the cases of milk sickness I have ever seen in women have followed immediately upon a washing-day, or a day of hard work in cooking or entertaining company, and I recall the case of one man who came up out of a well he was digging, and went directly to bed, where he died ten days later.

Among the livestock dealers in milk-sick districtsit has been the custom, since my recollection, to make one of the stipulations in a cattle trade to have the privilege of rumning the cattle for five, ten or fifteen minutes, as a test for their safety from trembles. If they had trembles, or were bordering on the disease, more or less of them would be likely to show it unmistakably, whilst running, or within a very few hours thereafter.

\section{PERIOD OF INCUBATION.}

'This, I think, must be somewhat uncertain. I recall the case of a young girl who was a servant in the family of one Dr. A. W. Field, at Amity, Madison Co., Ohio, about thirty years ago. Her fathers family, five miles distant, in the country, contracted milksickness, and she went to visit them on Sunday, before the true nature of the sickness had been pronounced. She stayed to dinner, and ate some butter on her bread, but no cheese, milk, or meats of any kind, and returned to the village in the afternoon. On Tuesday, the second day following, she came down with milk-sickness, but had a slow recovery, while all the balance of her father's family died.

In 1867 , in the month of August, I was called to see the case of the well digger before alluded to. He was a farmer, living in Pleasant township, Clark county, Ohio, and was digging a well for the use of his family, at his own house. I suspected milk-sickness. He acknowledged that his cows had "stayed out" two successive nights, about a week before, in the Baily Woods, a heavily timbered, unimproved body of land of several hundred acres, adjoining his little farm, and belonging to some minor heirs in Virginia. They declared their cows and calves were healthy; but I went into the barn lot and commenced chasing the calves, and in less than five minutes one of them developed into an unmistakable case of trembles.

The products of the dairy were used no more by any member of the family; but the wife, who was enciente, was taken two days after; and within a week I had five cases in the family, all of whom had a slow recovery excepting the husband, who was somewhat intemperate-and that class of cases generally die.

In August, I869, I was called to see S. M., on the National road, near the line between the counties of Clark and Madison, in Ohio, and within about three miles of the Baily Woods, before mentioned. Malarial remittents were then prevalent, and I failed to get a clear history of his case, as he was deaf and dumb, and his wife a poor interpreter. I concluded to prescribe quinine; which I had administered in whisky, to reconcile him to the bitter taste of the drug. On the following day I repeated the same; but on the third daily visit I found his wife sick, and I suspected milk-sickness. I ascertained that their cow had "stayed out" one nightabout a week before, and had probably stayed over night in the Baily Woods aforesaid. I went to the pasture and chased the calt around, but without developing any trembles; but by the next day I found the woman with a well-marked case of milk-sickness; and the calf dead of the trembles.

The husband made a good recovery, from a very mild case of milk-sickness, in which there was no vomiting, no retching, but simply the symptoms of the initial stage before vomiting supervenes; whilst the wife died on the twelfth day of her illness, and an only child, a boy, twelve years of age, escaped entirely.

In the winter of $1874-75$, I was called in consultation at night, with Dr. James B. Sprague, to see some cases in Brighton, Clark Co., Ohio.

I found the husband, aged about forty-five, a cooper by trade, in articulo mortis. I found his wife, about forty, in but a little better condition, as she died about twelve hours later.

Now the question in these cases was, where did the disease come from? A beef had been sold by retail through the town the previous week, and suspicion pointed to that as the cause; and the development of four additional cases in another family, about four days later, - all of whom had partaken of the suspected beef, seemed to strengthen the suspicion; although other families who bought of the beef escaped.

And then another question arises, where and when had the beef contracted the disease? That cattle may have trembles in the winter season, is a matter of occasional observation; and the old citizens generally attribute it to the feeding of cattle upon wild or swamp hay. And that suspected animal, it was ascertained, had been feeding from hay cut in a boggy meadow, over which about one hundred acres of the drainage of the aforesaid Bailey Woods spread itself as it sought the sluggish ditch running across the meadow.

The disease germ in the animal may have been incubating since the summer season; but it would seem quite as probable that it was attached to the grasses and survived until the proper nidus was found in the 
ingesta of the animal's stomach, when it started to activity and possible multiplication, like a germinating speck of yeast plant.

\section{SYMPTOMATOLOGY.}

In the lower animals the disease is called "trembles," from the agitated condition of the muscles in the animal affected.

The first symptom of the disease that is generally noticed, is that the animal is indisposed to exercise. It stands apart from the herd, drooping, languid, with a look of extreme fatigue, and persistently abstains from food.

The second stage is that of trembling, extreme thirst and obstinate constipation. The animal at length can no longer stand, and when it lays down seldom rises again. The decubitus becomes at full length, and the animal becomes a stranger to any manifestations of fear, affection or anxiety. The respirations are slow, the extremities and surface cool, and the eye at length fixed, glazed, and the winking ceases altogether. Death generally follows-occuring, ordinarily, from the eighth to the tenth day.

In milk sickness the patient is apathetic, complains of malaise, weakness, indisposition for exercise, loss of appetite or loathing of food, and sometimes of slight nausea. This condition may run on for several days, gradually becoming more pronounced, when vomiting supervenes, and the patient finally takes to his bed. There are no chills, no rigors, but usually an unsatisfied thirst. The tongue is large, flabby, tremulous, moist, and heavily loaded with a dirty white coating. The temperature of the surface sinks below that of normal. The skin is dry, and sensible respiration suspended. The abdomen is retracted and flabby, and comparatively empty. Peristaltic motion seems absolutely suspended; and from that cause, probably, and the general suspension of alimentary secretions, the bowels become, from the first, obstinately and persistently constipated.

The breath becomes offensive, with an odor that some people claim is peculiar to milk-sickness alone. I am led to believe that this may be so, but my observations do not fully confirm me in the belief. The urine becomes diminished, sometimes to eight or ten ounces a day, and generally clear and limpid. The pulse is variable as to frequency, but is always weak and easily compressible, with labored action of the heart and pulsating aorta. The temperature rises in some cases to $99^{\circ}$, but is usually below normal.

There is a marked degree of hebitude and indifference, and even in cases where the patient expresses no hope of recovery; the ordinary solicitude for the future of the family and friends is rarely alluded to.

There is an intolerance of covering for the body, especially of the extremities; and I recall one case in which the patient would give no rest to the nurses only as they kept his hands immersed in a basin of cold water; and the ordinary efforts resorted to for warming up the extremities usually are attended with an aggravation of the vomiting or retching.

As the disease advances, the exhaustion becomes so extreme that romiting is superseded by a feeble retching effort, that to be heard once is to be remembered always.
The patient seems to become more and more somnolent; but there is seldom oblivious sleep; and if there ever is, at all, it is of short and fitful duration.

The vomiting first, and the retching in the later stages, continues to the very close of life; or until coma and oblivion shut it off.

In the later stage the fluid ejections from the stomach are tinged like the indigo-blueing water used in laundries.

These symptoms increase as the disease advances; the hebitude assumes a semi-comatose condition; the respirations decrease in frequency, and are variablesometimes profound and sometimes scarcely perceptible-like the respirations of a hibernating animal. The prostration sometimes becomes profound, the process of winking suspended, and the conjunctiva and cornea become dry and glazed. The hebitude increases to somnolency, and the somnolency to a coma. There is stasis of the capillaries, and the vital forces, yielding one by one, the patient dies without a struggle and almost without a sign. Some cases are mild, like the one of the deaf and dumb man I have alluded to, and in bad cases, when recoveries take place, the convalescence is by slow and almost imperceptible stages. I think I never met with but one case in which there seemed to be a crisis, characterized by a sudden restoration of the functions. This was in the case of a child-a girl about twelve years old, in the family of the well-digger before alluded to. On about the tenth day of her sickness I gave up all hope of her recovery. For two days her coma had been continuous; the process of winking suspended for forty-eight hours, and all signs of vitality nearly suspended. Altogether unexpectedly to me she had a dejection, deep green in color, of about one quart, of the consistency of soft soap. Twelve hours later the respirations had increased by at least five in the minute, and she had been noticed to open and shut her eyelids four or five times. She gradually recovered.

\section{PATHOLOGY.}

The consumption of tissue in this disease is limited, and not like the consumption of tissue in continued fevers. There has been no tenderness over the epigastrium, or the bowels, and the post-mortem shows no characteristic symptoms of inflammation in any part of the alimentary canal. The stomach is found empty and the contents of the intestines consist principally of lumps of a dark-colored, dry, tenacious feculent matter-much the same in appearance as the evacuations, whenever they occur in these cases in the course of the disease. I think there are no special characteristic pathological symptoms by post-mortem unless it be the above named appearances of the contents of the intestines.

TREATMENT.

This, to a very great extent, has probably been empirical. The aborigines in Central Ohio, and possibly elsewhere, are said to have placed some reliance on the use of pulverized charcoal, suspended in milk. I used this not infrequently in the early days of $m y$ practice, and sometimes have thought that its persistent use did have an influence in allaying the nausea. 
Effervescent mixtures-carbonic-acid water or soluble citrate of magnesia, or lime water, however, have seemed to give me more satisfactory results, if I have ever had any satisfactory results from anything. Frequently repeated teaspoonful doses of pure olive oil was a favorite remedy in domestic practice; and I have used olive oil in four-ounce doses, repeated about four times a day, per rectum, but with no appreciable results. Emetics were sometimes used by the botanic physicians ; and drastic cathartics-calomel, jalap, etc. - by the rrgulars, in an eariy day; but probably only with the results of hurrying some off who might possibly otherwise have recovered. Mercury was not infrequently tried, as in mechanical obstruction of the bowels; but I never saw a case so ? treated which recovered, nor ever saw a globule of mercury that had been passed per anum.

I recall the cases of the first family into which I was called, professionally, in the capacity of a medical adviser, in cases of milk-sickness, in the autumn of 1853 . The family were residents of Darby township, Madison county, Ohio, on the banks of Little I) arby-a sluggish stream of two or three rods in width. One child was already a corpse, and the father died on the following day. There was another one of the family sick for four or five days; and I recommended the attending physician to give whisky and quinine-a remedy recommended probably for the first time in that settlement. I cannot say if my recommendation was carried out, but the patient recovered.

The next family was in the autumn of 1855 , in Monroe township, Madison county, Ohio. One of the cases, a young lady of eighteen, was in the fully developed stages of the disease, and died on the fifth day. Four others of the family - the mother who was enciente, in the sixth month, and three children, were simply in the prodromic stage,-with lassitude, hebitude, and slight nausea. There was consternation in the household when the disease was pronounced; and in the prodromic cases I advised stimulating doses of spiritus frumenti, every 4 hours, in the shape of punch, egg-nog, stews, with sugar, or with sugar or peppermint, or straight, as was most desirable to the patient, coupled wfth fresh slippery elm bark mucilage, as a drink, and avoidance of all unnecessary exercise ; and none of these four cases advanced to the stage of persistent vomiting, and all recovered within a week or ten days.

Within the last twenty years I have avoided the administration of active cathartics, - as there is suspended peristalsis during the pronounced stages of the disease,--and have confined myself generally to mucilage of fresh slippery elm as a drink, occasional small effervescing draughts, when agreeable to the patient, and alcoholic stimulants either per orem or per rectum, in all cases, with better general results than when I vacillated too much from this course, in the earlier days of my practice.

In "trembles" the domestic remedy that was of the most general adoption, was feeding the animal with green corn, freshly cut from the field. If the animal would eat enough to act as a cathartic, it would generally get well.
When I am called upon to prescribe I recommend four ounces of whisky to one quart of water, repeated every four hours. Deaths from trembles seldom occur when this is commen early in the case and followed up long enough; or. until convalescence begins.

\section{MECHANICAL REMEDIES IN THE TREATMENT OF SKIN DISEASES:}

BY JOHN V. SHOEMAKER, A.M., M.D., PHYSICIAN TO THE PHILADELPHIA HOSPITAL, FOR SKIN DISEASES.

[Read to the Section on Practice of Medicine, Materia Medica, etc., June, 1883.]

Genthexien: I do not propose to read my paper in extenso before the Section this afternoon, but while giving its salient points, I shall reserve for publication, in case of acceptation, its entirety.

There are a number of -remedies which can be used in the treatment of skin diseases which cannot be classed as drugs, but being mechanical in their application may be appropriately termed mechanical remedies.

They are massage, compression, blood-letting, incision, excision, enucleation, scooping, scraping, setons, and cauterization, remedial measures which have been in vogue almost from time immemorial, but which have been more or less lost sight of, and seldom, if ever, used by therapeutists in the treatment of cutaneous diseases.

These are all valuable agents, as I can attest from a long personal experience with them, and I now will . proceed to relate what can be accomplished with these mechanical appliances in skin diseases. I will begin with massage, - the first mechanical agent which I shall consider. Although long and favorably known as a general remedy it has, however, attracted little if any attention as a means of treating skin diseases. Its use upon certain morbid conditions of the integument, when properly applied, is often followed with marked beneficial change and at times with complete restoration of the part to its natural state. Massage not only acts in this way locally, but by its indirect effect when used generally, will add tone and vigor to the entire system. This direct as well as indirect action of this powerful mechanical remedy can thus be. put into execution both for its local and constitutional effect in many skin affections. Massage, if employed in its original sense, would simply imply kneading; it has now a wider and more general use, and includes as well a group of procedures known as friction, pinching, manipulation, rolling, and percussion of the different external parts of the body. It can be done with the hand or with the additional aid of some fatty substance, a coarse towel, a hair mitten or a brush. It may be performed also by means of ingenious machines that are now perfected and arranged for doing, what the most skillfull manipulator can do with his hands. It is better, should the hands be used, that the operator should be strong, muscular if possible, possessed of activity and energy, cheerful and intelligent, with some knowledge of anatomy and physiology. If he has not these latter acquirements 